\title{
Screening for disability: a eugenic pursuit?
}

John Gillott Genetic Interest Group, London

\begin{abstract}
This article is written in response to the idea that selective termination may be eugenic. It points out that a mixture of motives and goals may inform screening programmes and selective termination for fetal abnormality without the intention being "eugenic". The paper locates modern genetics within the tradition of humanist medicine by suggesting that parents who choose to terminate a pregnancy because of fetal abnormalities are not making moral judgments about those who are living with these abnormalities already. Rather they are making judgments about their own lives and the lives of their children in relation to this genetic disorder. It concludes by introducing several caveats about the counselling that parents receive after the results of the testing and suggests that counselling inevitably contains a directive element because of the nature of the information covered.

(Fournal of Medical Ethics 2001;27 supp1 II:ii21-ii23)
\end{abstract}

Keywords: Eugenic; termination; disability; genetics; disorder; parents

Some people reject antenatal genetic testing because they object to abortion as such. This is a familiar debate and, in the spirit of exploring the new ethics of abortion, not one that I intend to rehearse here. Instead, I want to focus on concerns about the selective aspect of selective termination and about screening programmes that may precede such terminations-concerns that are often, if not typically, voiced by people who are in general prochoice. ${ }^{1}$ The critical literature on this is expanding rapidly and becoming slightly more differentiated in the process. In this paper I look at one aspect of the debate by addressing the question: screening for disability: a eugenic pursuit?

The decision to undergo genetic testing during pregnancy rests with the woman, usually after consultation with her partner. When there is a family history of a genetic condition, the initiative, the initial suggestion that testing could be used, will usually come from the woman. In the case of population screening it is health professionals who take the initiative. For example couples might be offered screening with the aim of determining whether they are carriers for a condition; if they are and a pregnancy is established, antenatal testing will be offered.

For Modell, Harris and colleagues, ${ }^{2}$ the purpose of such carrier screening is to "permit couples who are at risk an informed choice among available options, including prenatal diagnosis in every pregnancy". A reduced birth incidence of the condition in the population as a whole might be an outcome, but it is not the aim. Others present things rather differently. Writing about cystic fibrosis (CF), Murray, Cuckle and colleagues ${ }^{3}$ boldly state that: "the aim of genetic screening for CF is to reduce the birth prevalence of the disorder. This is primarily achieved by identifying carrier couples who can have prenatal diagnosis and selective termination of pregnancy".

The truth of the matter is probably that both aims inform screening and testing programmes. However the issue is posed, the primary choice, in screening and also in patient-initiated testing is to avoid the birth of a child with a genetic condition. Is this eugenic? There are a number of variations of the argument which suggest that it is. These different aspects of argument are put with varying degrees of vigour by different critics of antenatal screening and selective termination, and clearly, whether or not these procedures are thought to be "eugenic" will depend on what that emotive term is taken to mean.

In this brief presentation of the arguments I cannot hope to do justice to the full range of opinion and writings on the subject. I do hope, however, to establish that the values of modern medical genetics are fundamentally different from those of the main strands in historical eugenics, and that approval for genetic testing prior to birth is compatible with equal treatment for people living with disabilities.

Francis Galton defined eugenics as the scientific study of the biological and social factors which improve or impair the inborn qualities of human beings and of future generations. Such study suggests a practice of eugenics. A modern definition might be any policy that alters the composition of the human gene pool. The philosopher Philip Kitcher ${ }^{4}$ develops this interpretation in his thoughtful book The lives to come: the genetic revolution and human possibilities. He then subdivides the notion into different types. Interestingly, he also characterises doing nothing when we have the ability to do something as eugenic. At this point the critics of genetic testing part company with him. For them, eugenics is about humanity changing the gene pool, specifically reducing the incidence of genetic disorders, whether it is government policy or the aggregate of individual decisions that brings this about.

Both Kitcher's and the critics' notions have their merits. But posing the issue in such a general way also tends to obscure crucial differences between historical eugenics and modern genetics. At the turn of the century there was a widespread belief that genetics influenced morals and personality 
traits. The preoccupation was with controlling the spread of these traits, rather than medical conditions. The dominant strand in eugenics of old was a state-led drive to alter the gene pool, in some cases by coercive measures. It was used to justify the sterilisation, and even murder, of people classed as mentally insane and genetically inferior.

At the time, not enough was known about genetics and disease/behaviour to highlight the scientifically irrational character of many of the eugenic proposals. Enough was known, however, about population genetics by 1920 to invalidate, on scientific, never mind humane grounds, eugenic arguments for sterilisation. That such programmes continued regardless highlights perhaps the most important point to understand about the dominant strand of old eugenics: it was driven neither by science nor by humanitarian concern but by a strong political belief and fear-of national, racial, and social decline. As the historian Daniel Kevles ${ }^{5}$ puts it, using the example of Britain at the turn of the century: "To many British, the general fibre of the nation-its overall moral character, intelligence, energy, ambition, and capacity to compete in the world-was declining".

After the second world war, eugenic practices continued for some time, up until the 1970s in the case of Sweden. Eugenicists sought to pursue their goals through the new field of reproductive and genetic counselling, and some still believe that the moral worth and future of nations depend upon genetics. But in my view the predominant ethos of all work in human genetics today, and in medical genetics in particular, has little or nothing in common with historical eugenics.

The new genetics is concerned more with identifiable medical diseases than with personality traits and behaviours. It represents a biological approach to biological problems, not a reductionist approach to the whole human being. This is not to say that modern behaviour genetics and the genetics of mental health are marginal fields of inquiry; they are not. But leading researchers in the field understand the limited contribution of many different genes. Their study is primarily individual variation, not purported race or social-group differences, and very few working in the field link genetics to ideas of racial or national success and failure. Finally, these areas of genetics do not impinge on services offered prior to implantation or birth, and are unlikely to do so for the foreseeable future.

Some within the disability rights movement might accept the distinction I have drawn, but continue to object to antenatal testing and screening because they believe it necessarily devalues those living with the condition. Focusing on the motivations of parents in the first instance, I believe that this is wrong, and that the critics are guilty of conflating impairment and the moral status of people-something they often accuse supporters of testing and screening programmes of doing.

I have located modern genetics within the traditions of humanistic medicine. Clearly, selective termination, a possible outcome of one aspect of genetic science, is not a "cure" or treatment. I would argue, however, that parental attitudes towards fetal abnormality are framed by attitudes towards illness and not unreasonable expectations about the impact of such genetic disorders on their own and their children's lives. If they choose to terminate an affected pregnancy they are making a judgment about impairment, which is the level at which antenatal selection operates, and a guess about the life they, and a child with the particular condition, would have, given existing levels of medical knowledge and social support. That judgment is a relative one ie that life without the condition is better than life with it. Parents are not, as the caricature sometimes has it, saying that life with a genetic disorder is not worth living or is too terrible to contemplate. And certainly, they do not see themselves as making a moral judgment about the worth or rights of people living with that genetic condition.

In conclusion I want to suggest that not only does the service not have the faults attributed to it, but the arguments of the critics could add to the faults in the service as it exists, and may hinder its future development. In short, the danger is one of poor guidance and restrictive regulations.

It is the Genetic Interest Group's experience that some parents are left to make their decisions in a vacuum because health professionals fear being seen as directive if they fully discuss the available options. Genetic counselling is concerned with facilitating informed reproductive decisions. Following the eugenic experience prior to the first world war, the emphasis has always been placed firmly on the "non-directive" part of "non-directive genetic counselling". This is as it should be. But I would introduce the following caveats:

(1) There is a danger of making anything appear directive. Some say presenting testing as part of antenatal care is directive, or that clarifying likely implications of a condition is directive, or that ensuring that risks are properly understood is directive. All these procedures should rather be seen as perfectly reasonable features of patient care, and quite consistent with the goal of informed choice. I note that in one study, patients expressed satisfaction even when they thought aspects of their care were "directive".

(2) We cannot avoid the fact that the primary choice offered by these services is the choice to avoid having a child with a genetic conditionand that this is the choice made by most people. If this is directive then non-directive genetic counselling is impossible (a majority of delegates to the Third European Meeting on the Psychological Aspects of Genetics, held in 1992, took this point of view).?

(3) A rigidly applied policy of non-directiveness may not meet patients' needs in all circumstances. Certainly, in a screening context, if a family is unaware of the nature and implications of the condition that may affect a future child and if the goal is indeed informed choice, 
then it is the duty of the health professionals to present the family with the facts, and to inform them about the reality of the condition. As Modell and colleagues point out in their study of screening services for thalassaemia during pregnancy, ${ }^{2}$ the fact that this is not happening in many cases means that families are being denied the chance to make a choice.

Turning to the issue of the law and regulations, I think it would be fair to say that there is a deliberate element of ambiguity in relation to selective termination. Both the law and regulations are framed in such a way as to allow individuals and clinicians to come to an arrangement that meets individual needs in most cases. But they are also framed so as to deny absolute individual freedom of choice as a matter of principle. Thinking on antenatal screening appears to be in a more genuine state of confusion. Partly because of this, and partly because of issues relating to finance, it is proving difficult to formulate a national antenatal screening strategy. For the critics, the ambiguity in the law on selective termination is a source for concern. They would prefer it to be tightened up. Many would also like to limit the development of screening programmes, and perhaps restrict the range of conditions for which genetic testing in early pregnancy is allowed.
We might want to be debate whether regulations should rather be liberalised further. But certainly, if the law was to be interpreted in a less "permissive" way than currently, and the option of testing denied, it would be hard to avoid the conclusion that real-life choices were being denied.

Fohn Gillott is the Policy Officer at the Genetic Interest Group, London.

\section{References}

1 Parens E, Asch A. The Disability Rights Critique of Prenatal Genetic Testing. A special supplement to the Hastings Center Report 1999; Sept-Oct:s12.

2 Modell B, Harris R, Lane B, Khan M, Darlison M, Petrou M, et al. Informed choice in genetic screening for thalassaemia during pregnancy: audit from a national confidential inquiry. British Medical fournal 2000;320:337-41.

3 Murray J, Cuckle H, Taylor G, Littlewood J, Hewison J. Murray J, Cuckle H, Taylor G, Littlewood J, Hewison J. Screening for cystic fibrosis;

4 Kitcher P. The lives to come: the genetic revolution and human possibilities. London: Allen Lane, The Penguin Press, 1996.

5 Kevles D. In the name of eugenics. Berkeley and Los Angeles: University of California Press, 1985:73

6 Michie S, Bron F, Bobrow M, Marteau TM. Nondirectiveness in genetic counselling: an empirical study. American fournal of Human Genetics 1997;60:40-7.

7 Abramsky L, Chapple J, eds. Prenatal diagnosis: the human side. London: Chapman and Hall, 1994: 74-5. 